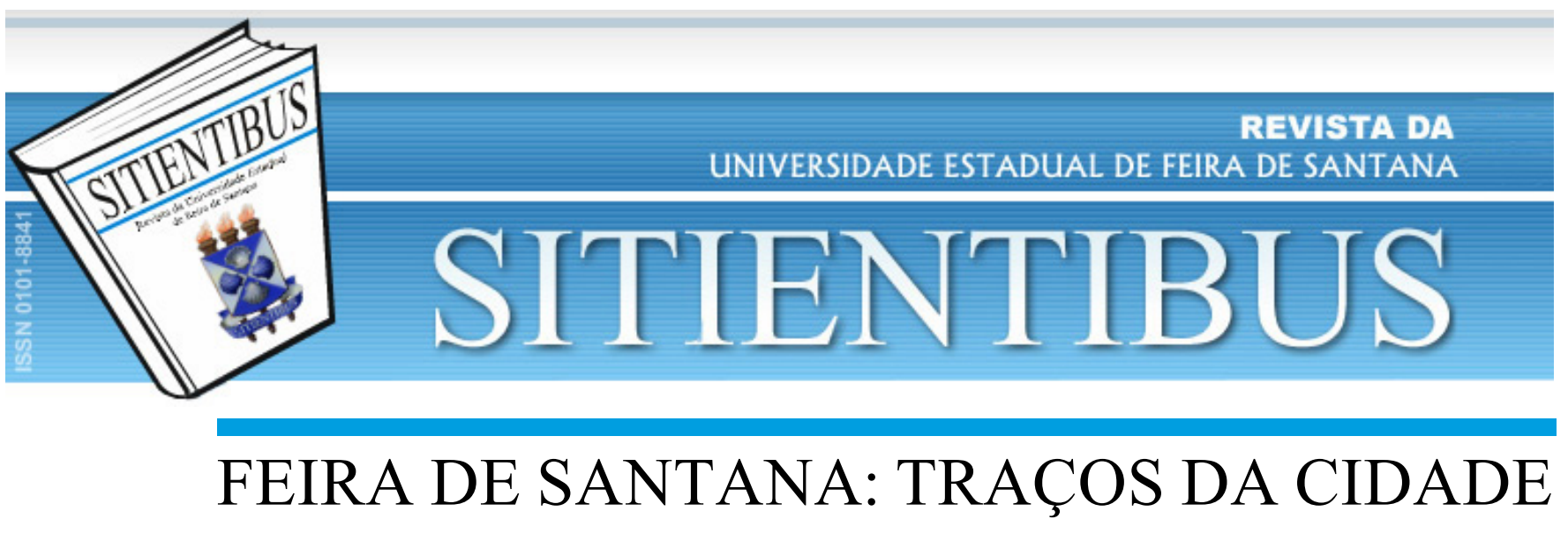

ARTIGO

\title{
FEIRA DE SANTANA: ASPECTOS HISTÓRICOS DA URBANIZAÇÃO SOB A ÓTICA DA MOBILIDADE URBANA
}

\section{FEIRA DE SANTANA: URBANIZATION HISTORICAL ASPECTS UNDER THE URBAN MOBILITY POINT OF VIEW}

\section{RUY DE SOUZA REIS}

Mestre em Planejamento Territorial/UEFS. Pós-Graduado em Direito do Trabalho e Processo do Trabalho/Faculdade Damásio. Pós-Graduado em Direito de Estado/FAT Graduado em Administração/UEFS. Graduado em Direito/FAT. E-mail: ruyreis.adv@outlook.com

\section{RESUMO}

O presente artigo tem como linha principal os aspectos históricos da urbanização sob a ótica da mobilidade urbana, no âmbito do município de Feira de Santana-Bahia, e suas transformações até chegar ao status atual. Compreende isso com base na evolução histórica de Feira de Santana, seu surgimento e desenvolvimento como marcos para entender o processo de crescimento urbano e o surgimento dos problemas da mobilidade na cidade. O texto utilizou como procedimentos metodológicos: pesquisa bibliográfica, documental e exploratória, e retrata os eventos considerados como vetores de crescimento de Feira de Santana, os dados demográficos ao longo das décadas e os movimentos migratórios do campo para a cidade e o consequente crescimento da frota de veículos no município, no horizonte de 2001 a 2016. A análise dos aspectos históricos e os vetores de crescimento da cidade, aliado ao crescimento da frota de veículos, permitem então entender o que ocorre, nas últimas décadas, na mobilidade urbana.

Palavras-chave: Mobilidade urbana. Urbanização. Aspectos históricos. Feira de Santana.

\section{ABSTRACT}

The main line of this article are the historical aspects of urbanization from the point of view of urban mobility, within the municipality of Feira de Santana-Bahia, urban mobility and its transformations until reaching the current status. It is understood with basis on the historical evolution of Feira de Santana, its emergence and development as milestones to comprehend the process of urban growth and the emergence of urban mobility problems in the city. The study used bibliographical, documentar and exploratory research as methodological procedures, and it portrays the events considered as vectors of growth in Feira de Santana over the years. It also uses demographic data over the decades, as well as the migratory movements from the countryside to the city and the consequent growth of the vehicle fleet in the municipality, from 2001 to 2016 . The present study is part of a technical report of the Master's Degree developed by the author, which proposed to address the problems of urban mobility in Feira de Santana.

Keywords: Urban mobility. Urbanization. Historical aspects. Feira de Santana. 


\section{INTRODUÇÃO}

Nas últimas décadas, as regiões metropolitanas brasileiras passaram a viver um problema de complexa mensuração, que são os congestionamentos urbanos. Tais congestionamentos preocupam não só os indivíduos, mas também os entes governamentais. A sensação de tempo perdido diante de um enorme congestionamento é muitas vezes preocupante, e poucas pessoas sabem conviver com essa realidade naturalmente. Esse cenário faz com que as pessoas percam tempo e dinheiro por conta dos congestionamentos e é notório que há um aumento considerável no tempo e no preço das viagens de automóveis durante os congestionamentos. Nesse contexto, a busca por melhorias na mobilidade urbana tem sido um desafio constante enfrentado pela maioria das grandes cidades brasileiras. (BERTINI, 2005)

Essa nova lógica urbana demanda instrumentos e ferramentas que agilizem o deslocamento de bens e pessoas com eficiência, conforto e segurança. Outra preocupação constante é que esses meios utilizados reduzam os impactos ambientais, visuais e de poluição sonora e atmosférica, garantindo a tão buscada sustentabilidade.

É nesse sistema que o planejamento voltado para a mobilidade no longo prazo se faz imprescindível. Como o Brasil historicamente adotou o modelo predominantemente rodoviário, as metrópoles brasileiras sofrem com os congestionamentos e com elevado custo no preço das tarifas, ao ponto de ofertas de serviços precários, ineficientes e defasados que acabam por acarretar significativa diminuição da qualidade de vida dos indivíduos. Dentre as estratégias de melhoria e aperfeiçoamento da mobilidade urbana, as iniciativas públicas e privadas devem priorizar o gerenciamento de transporte coletivo, que desenvolvam uma logística de integração local e regional, e fomentem a melhoria da qualidade de vida. (LIMA, 2015)

Feira de Santana possuía, em 2016, uma frota de 252.696 veículos (DENATRAN, 2016). Essa frota de veículos experimentou um crescimento gradual nas últimas décadas. Acompanhando essa expansão apareceram também os problemas comumente encontrados nas cidades médias brasileiras, principalmente quando o assunto são as dificuldades nos deslocamentos: falta de infraestrutura, congestionamentos e transporte coletivo precário.

O tema abordado tornou-se central no debate pois se transformou no grande desafio atual das nossas metrópoles, face a deterioração do sistema de transporte coletivo e da precarização das condições de deslocamento nas áreas metropolitanas.

De acordo com dados do Censo de 2010, para chegar aos seus locais de trabalho, aproximadamente 24,2 milhões de pessoas se deslocam diariamente pelas 15 metrópoles brasileiras. Desse total, 6,8\% levam o tempo de até cinco minutos no trajeto casa-trabalho e $39 \%$ gastam entre seis minutos e meia hora no mesmo trajeto. Desse mesmo total de pessoas, outros 33\% gastam entre meia hora e uma hora e, aproximadamente, $21 \%$ leva mais de uma hora no trajeto entre sua residência e seu local de trabalho. Estudos recentes do Instituto de Pesquisa e Planejamento Econômico (IPEA) mostram, ainda, que na totalidade das regiões metropolitanas do Brasil entre 1992 e 2009 ocorreu considerável aumento no tempo médio de deslocamento de casa para o trabalho (PEREIRA; SCHWANEN, 2013).

Essa sensação de imobilidade, associada com a crescente precarização das condições dos deslocamentos, principalmente quando se tratam de cidades grandes, médias ou regiões metropolitanas, tem despertado o interesse da comunidade, inclusive acadêmica, na criação de um debate público sobre o tema da mobilidade urbana. Essa questão anteriormente aparecia com mais frequência no noticiário em geral, nos veículos de informação da internet, nos debates nas redes sociais, em websites oficiais do governo. Todavia, nos últimos anos, tem aparecido com mais presença, também, nas publicações acadêmicas, em virtude da sua relevância e importância cada vez mais notável que o tema tomou.

O presente artigo tem como linha principal os aspectos históricos da urbanização sob a ótica da mobilidade urbana, no âmbito do município de Feira de Santana, e suas transformações até chegar ao status atual. Utilizou-se como procedimentos metodológicos: pesquisas bibliográfica, documental e exploratória, para retratar os eventos considerados como vetores de crescimento da cidade, com base em dados demográficos ao longo das décadas, dos movimentos migratórios do campo para a cidade e do consequente crescimento da frota de veículos no município, no horizonte de 2001 a 2016.

O texto inicia com a análise sobre o que se entende por mobilidade urbana. Depois, parte para os aspectos históricos da mobilidade urbana no âmbito do município e, por fim, a relação entre urbanização e mobilidade urbana no âmbito de Feira de Santana, tendo a evolução da sua frota de veículos, o crescimento populacional e o aumento da taxa de urbanização como os focos principais.

\section{NO QUE CONSISTE A MOBILIDADE URBANA?}

O conceito de mobilidade urbana, adotado pela maioria dos autores, refere-se às condições de deslocamento da população dentro do espaço das cidades, o que merece certo questionamento. O termo é empregado, em regra, para referir-se ao trânsito de veículos e pedestres, seja ele por meio do transporte individual (carros, motos, bicicletas etc.), seja através do uso de transportes coletivos (ônibus, bondes, metrôs etc.). (PENA, 2015)

A mobilidade urbana é o resultado de um conjunto de políticas públicas de transporte e circulação que buscam proporcionar um acesso amplo, facilitado e democrático ao espaço urbano, com a priorização dos meios de transporte 
coletivo e não necessariamente motorizados de modo efetivo, com vista a efetivação de uma política socialmente inclusiva e com sustentabilidade ecológica. (SIQUEIRA; LIMA, 2015)

Os congestionamentos, além de significar desperdício de tempo e dinheiro, terminam por provocar estresse e geram mais poluição ao meio ambiente. Nas últimas décadas, esse problema tem se agravado, principalmente nas grandes metrópoles brasileiras. (RESENDE; SOUZA, 2009)

A falta ou o limite na mobilidade também causa grande impacto na economia, o que faz o país crescer de maneira mais lenta, prejudica sua competitividade e diminui a produtividade, o que leva, por consequência, a indústria e atividades a essa relacionadas a sofrerem decorrências de monta em sua produção. (QUEIROZ, 2015)

\section{ASPECTOS HISTÓRICOS DE FEIRA DE SANTANA}

De acordo com historiadores, o surgimento do município de Feira de Santana remonta a meados do século XVII, período em que se deu o povoamento inicial da sua região oriundo, principalmente, da criação de gado e instalação de currais. Esse povoamento originou-se com a doação de terras pelos reis portugueses a alguns de seus súditos. No caso de Feira de Santana, a Família Peixoto Viegas era a detentora das terras às quais teve início o município, chamadas Jacuípe, Água Fria e Itapororocas. (IBGE, 1958)

Essa vocação para sediar centros de criação e engorda de rebanho bovino resultou, entre os séculos XVII e XVIII, numa crescente concorrência de pessoas que periodicamente vinham para essas terras, o que favoreceu a implantação de um pequeno arraial e, com o passar dos meses, de uma feira semanal. (IBGE, 1958)

Essa feira semanal proporcionou o surgimento do comércio feirense que, além de favorecer a economia local, configurava-se como uma das características marcantes da sociedade que a incentivou. A influência, a princípio comercial, ampliou-se em decorrência da rota que ligava o sertão ao litoral, o que concedeu a localidade uma importância crescente ao cenário regional da época. (IBGE, 1958)

Ainda na primeira metade do século XVIII, a povoação já era um centro de trocas e escambos. Do comércio que começava a surgir nasceu uma pequena feira livre, que era realizada sempre às segundas-feiras. Esse desenvolvimento forçou a abertura de ruas que se adequassem a esse grande fluxo de feirantes oriundo de diversos locais e, com isso, a população cresceu e as primeiras lojas foram surgindo. (IBGE, 1958)

A feira tornou-se parte da vida econômica e social de toda a circunvizinhança e suficientemente importante para a área ser considerada um arraial florescente junto à capela de Santana dos Olhos d'Água. (POPPINO, 1968)

Em 13 de novembro de 1832, o povoado de Feira de Santana foi elevado por decreto imperial à categoria de vila, e passou a ser, então, a sede do recém-criado município de Feira de Santana, uma vasta zona de mais de 12.000 quilômetros quadrados desmembrados do município de Cachoeira. Essa nova unidade administrativa abrangia a maior parte da atual área compreendida pelos municípios de Feira de Santana, Ipirá, Riachão do Jacuípe, Conceição do Coité, Serrinha, Irará e Coração de Maria. (POPPINO, 1968)

Com o crescimento da vila e sua posterior elevação à categoria de cidade, várias pessoas construíram barracos feitos de taipa ou sopapo e cobertos de palha e novas fazendas foram construídas, como São João, Muchila, Usina de Algodão. Surgiu então a Praça da Estação - hoje, Praça Presidente Médici - atualmente, onde funciona o mercado popular conhecido como Feiraguai. Pela Chácara dos Padres passavam os transeuntes que viajavam a pé. O local ficou conhecido como Rua do Padre - hoje, Macário Cerqueira -, por essa rua ia-se a pé até a cidade de Cachoeira.

Em 1917, o governo da Bahia traçou o primeiro de uma série de planos para a construção de uma rede de estrada de automóveis, que ligariam todas as regiões do Estado, uma vez que a introdução do automóvel e do caminhão ocasionou uma revolução na construção de estradas no Estado da Bahia. Os caminhos para animais e cargas não eram convenientes para veículos a motor e, em decorrência disso, os homens de negócios que saudaram o novo meio de transporte começaram a exigir melhores caminhos e as autoridades estaduais e municipais começaram se empenhar para atender a essas solicitações. (POPPINO, 1968). Desse modo, a cidade foi "urbanizando-se" e o primeiro calçamento feito com paralelepípedos foi o da Praça da Matriz e da Rua Conselheiro Franco, época em que foi instalada na cidade uma agência do Banco do Brasil. (MORAIS, 2004)

Feira de Santana foi, em 1919, apelidada por Ruy Barbosa de "a Princesa do Sertão", e traz, então, desde sua origem, características marcantes que até hoje fazem parte de seu cotidiano: a religiosidade de seu povo, a situação de entroncamento de estradas e principalmente as intensas atividades econômicas. (FEIRA DE SANTANA, 2017)

Na década de 1930 e na década seguinte, Feira de Santana enfrentou uma série de transformações que atuaram sobre o município, modificando-o. Essas transformações permitiram uma modernização, a princípio de cunho econômico, que também repercutiu sobre as feições agrárias que o município possuía até então. (IBGE, 1958)

Nesse cenário, a urbanização de Feira de Santana começou a mostrar seus primeiros traços. Sobrevieram a construção de estradas de rodagem, que possibilitaram o aumento do fluxo de pessoas e que motivavam o crescimento populacional da cidade e impulsionaram seu setor terciário, o que, por outro lado, deu início às possibilidades de industrialização, como exemplo foi fundada uma usina de beneficiamento de algodão. Feira de Santana, que teve início na sua força de atividade rural, passava então a delinear, a partir desse período, um processo de renovação, o que, a cada ano, a fez ter um lugar de destaque no cenário econômico 
da região.(IBGE, 1958). Esse processo de desenvolvimento cultural, econômico e industrial se mostrou crescente nas décadas de 1940, 1950 e 1960.

Em 17 de junho de 1945, durante a primeira fase da Era Vargas, especificamente no período de declínio do denominado Estado Novo, foi fundada a Associação Comercial e Empresarial de Feira de Santana. Nesse mesmo período, ocorreu a abertura de várias estradas municipais. $\mathrm{O}$ início da construção e conclusão da Rodovia Feira-Salvador, a antiga BR-28, atualmente a Rodovia Engenheiro Vasco Filho, trecho da BR-324, a inauguração da Radio Sociedade AM de Feira de Santana, a pavimentação de várias artérias da cidade, a construção da Biblioteca Municipal e do Matadouro Municipal, a inauguração do Fórum Desembargador Felinto Bastos, a Estação Rodoviária e o Parque Agropecuário João Martins da Silva, dentre outros acontecimentos destacáveis que mudaram a rotina do povo feirense. (IBGE, 1958)

Em meados do mesmo período, Feira de Santana sofreu uma grande transformação, pois o Estado, através do governo federal que já havia implantado a BR-324, implantou também a BR-116, conhecida como Rio-Bahia, o que afetou claramente seu eixo de expansão. A união dessas importantes rodovias se deu atravessando o Centro da cidade, que na sua parte interna é denominada de Avenida Presidente Dutra, passando pela Praça da Igreja Matriz (Nossa Senhora Santana). Esse fato modificou a dinâmica local, haja vista que incentivou e reforçou o centro comercial e de serviços. Aliase a isso, a construção de parte do anel viário da cidade, para que o tráfego de veículos com carga pesada passe pela área externa ao meio urbano. (SANTO, 2012)

Em 1950, a cidade de Feira de Santana já era a mais populosa do interior do Estado da Bahia, com 26.559 habitantes. Na década anterior, em 1940, Feira de Santana ocupava o 4.ㅇ lugar. (IBGE,1958)

A partir de 1950, em decorrência da integração de Feira de Santana com o sistema de transportes rodoviário e da sua condição de grande centro comercial e pecuário do semiárido baiano, a cidade cresceu em ritmo acelerado, com um afluxo de migrantes de várias regiões baianas e do Brasil, principalmente do Nordeste. (CARMO, 2009)

Além das obras federais com a construção das rodovias, o poder municipal abriu novas avenidas no sentido Norte-Sul, as quais se destacam a Maria Quitéria; a Padre Anchieta, hoje denominada João Durval Carneiro; e a José Falcão da Silva, que geraram novas áreas de expansão. Cabe ainda destacar que, nesse período, muitas chácaras começaram a ser loteadas, principalmente nas proximidades das avenidas Maria Quitéria e João Durval Carneiro, sob a área do Tabuleiro Interiorano (SANTO, 2012)

A partir de meados das décadas de1960 e início dos anosde 1970 observou-se um processo de crescimento industrial. Nessa época, foram criados o Centro das Indústrias de Feira de Santana (CIFS) e também o Centro Industrial do Subaé(CIS). Essas implantações mudaram a fisionomia do município e colocaram a cidade em uma posição de destaque dentre as regiões mais industrializadas do Estado da Bahia. (CIFS, 2017)

Com o crescimento industrial adveio também um crescimento da população urbana e, nesse mesmo período, ocorreram mudanças no setor de habitação. Foi criado no ano de 1969 um conglomerado habitacional da URBIS, os Conjuntos Feira I e Feira II, que posteriormente foram transformados no bairro que atualmente é conhecido como Cidade Nova, primeiros conjuntos do gênero em Feira de Santana. (FALCÃO; CAMPOS, 2008)

Durante esses trinta anos, entre as décadas de 1940 e 1960, segundo informes dos censos do IBGE (1940, 1960), verificou-se em Feira de Santana a instalação de 254 estabelecimentos industriais de pequeno porte, com investimentos em sua grande maioria de origem local, com produção direcionada para o mercado local e regional. (CARMO, 2009)

Finalmente, em 1976, foi fundada a Universidade Estadual de Feira de Santana (UEFS), na parte Norte da cidade, o que representou mais um passo na caminhada do desenvolvimento para o município e sua região de influência, nasceu como resultado de uma estratégia governamental com o objetivo de interiorizar a educação superior, até então, circunscrita à capital, Salvador. (UEFS, 2017).

Esse fato atraiu pessoas de outras localidades e instigou ainda mais o crescimento da cidade, ao passo que impulsionou a expansão urbana em sua direção. No período considerado entre 1967 a 1986, se observa uma grande expansão da mancha urbana de Feira de Santana. (SANTO, 2012)

Em 1977, a feira semanal foi transferida para um moderno Centro de Abastecimento, construído especialmente para abrigar, em grandes pavilhões, os comerciantes que ocupavam até então o centro comercial da Cidade. (FEIRA DE SANTANA, 2017)

A década de 1980 e a primeira metade dos anos de 1990 confirmaram o franco crescimento do município de Feira de Santana nas mais diversas áreas, enquanto polo de atração de investimentos, o que manteve a sua vocação original de centro comercial, mas foram ampliadas as possibilidades de outrora e criadas novas perspectivas no âmbito da indústria moderna. (FEIRA DE SANTANA, 2017)

Atraída pelo comércio forte e pela encruzilhada que facilita passar por Feira de Santana, a cidade tinha em 2016 a segunda frota de veículos da Bahia com 112.948 veículos, sendo 112.948 automóveis e 72.834 motocicletas. (DENATRAN, 2016)

\section{A POSIÇÃO ESTRATÉGICA DE FEIRA DE SANTANA}

Cidade popularmente conhecida como Princesa do Sertão, Feira de Santana está situada a 108 quilômetros de Salvador, capital baiana, se ligando a ela através da Rodovia $\mathrm{BR}-324$, possui uma área de $1.337,993 \mathrm{Km}^{2}$ (ver Mapa 1). Em população, é a segunda cidade do Estado da Bahia e uma 
das maiores cidades dentre as que não são capitais, sendo também uma das principais e mais influentes do interior da região Nordeste. O município possuía, em 2010, 556.642 habitantes (IBGE, 2010) de acordo com dados do Censo e uma população estimada de 622.639 habitantes para 2016 (IBGE, 2016).

Desempenha importante papel de entroncamento do tráfego advindo do Sul e do Centro-Oeste do Brasil em direção a Salvador e outras cidades do Nordeste. Feira de Santana possui, atualmente, o maior centro urbano, político, educacional, tecnológico, econômico, imobiliário, industrial, financeiro, administrativo, cultural e comercial do interior da Bahia e é também um dos principais do Nordeste. Desse modo, exerce influência sobre outros municípios baianos, considerada capital regional B, conforme apontam dados do REGIC - Regiões de Influência das Cidades (IBGE, 2008).

O Mapa 1 ilustra a divisão territorial atual do município de Feira de Santana, com a sede do município e seus distritos, os municípios circunvizinhos, bem como as rodovias estaduais e federais que cortam o seu território.

Conforme se vê a partir do Mapa 1 a localização de Feira de Santana é privilegiada, a sede do município é cortada pela BR 116 e pela BR 324, o que facilita a entrada e saída de pessoas e mercadorias.
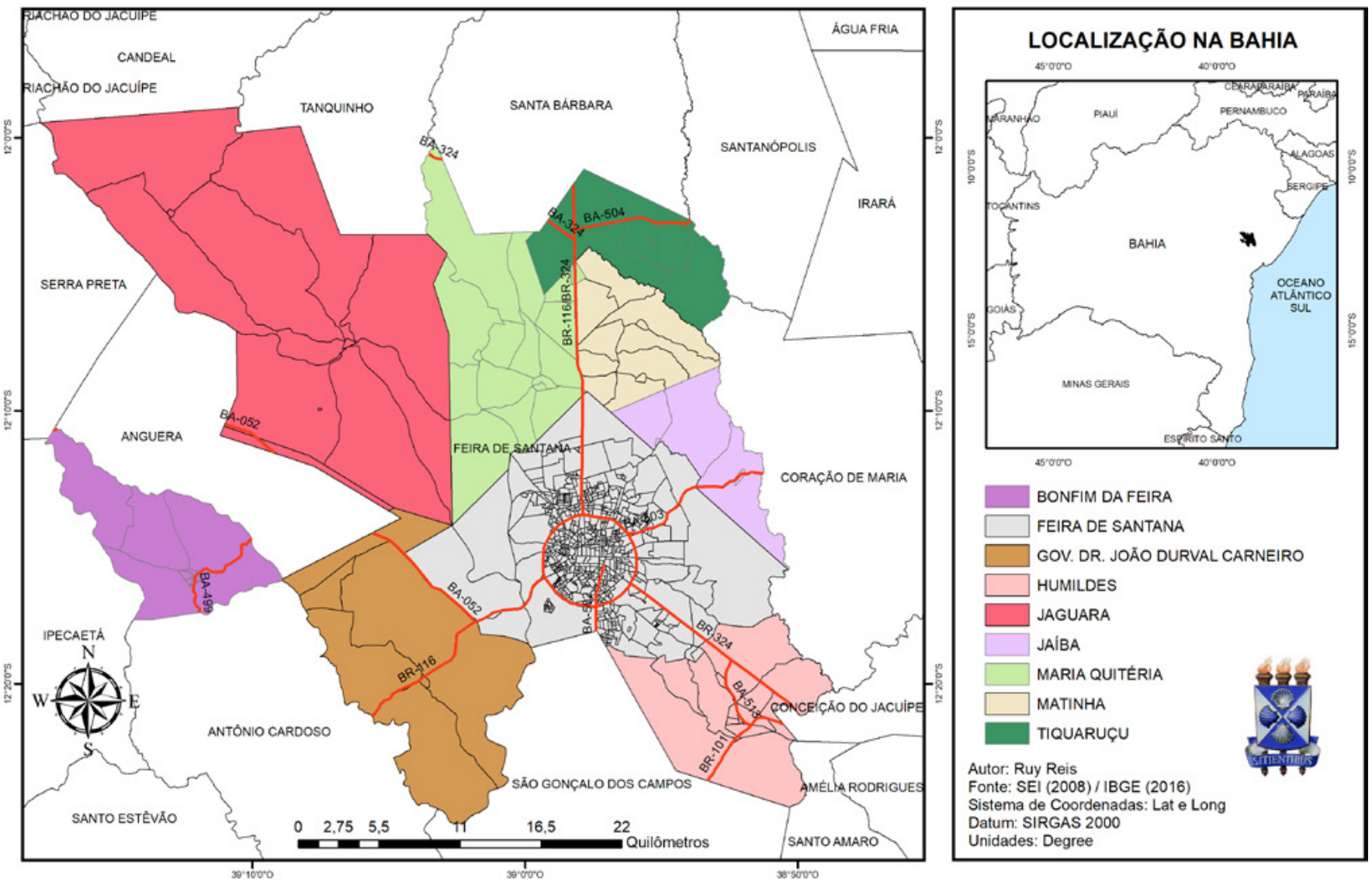

Mapa 1 - Divisão territorial, distritos e localização de Feira de Santana - BA, 2018.

A cidade tem um polo industrial em expansão, atrai moradores de cidades vizinhas e fica no cinturão de crescimento da capital, assim chamada a área em torno de Salvador com distância inferior a $200 \mathrm{~km}$. O problema é que o que hoje é visto como potencial poderá, no entanto, se provar uma armadilha, em virtude dos problemas de mobilidade e infraestrutura. Para fugir disso, o município tem de resolver problemas na infraestrutura que podem impedir um ciclo virtuoso do seu crescimento. (UPB, 2017)

Já na década de 1950 Feira de Santana era servida por oito estradas de rodagem que eram consideradas de primeira categoria, sendo 5 federais e 3 estaduais. (IBGE, 1958). Ligase a capital do Estado quase em linha reta, distante apenas $108 \mathrm{~km}$. Com os municípios vizinhos as ligações rodoviárias que se destacam são: Coração de Maria (43km), Irará (54km), Riachão do Jacuípe (75km), Santo Amaro (47km), Santo Estevão $(42 \mathrm{~km})$, São Gonçalo dos Campos (30km), Serra Preta (53km) e Serrinha $(68 \mathrm{~km})$.

\section{URBANIZAÇÃO E MOBILIDADE URBANA DE FEIRA DE SANTANA}

Feira de Santana é um dos maiores entroncamentos rodoviários do país, possui o terceiro maior PIB da Bahia, é composta de uma área de três polos industriais e, mesmo assim, possui problemas de infraestrutura e logística, é uma das principais cidades do interior do Brasil e sofre para se tornar acessível por outros modais além do transporte rodoviário. (UPB, 2017) 
Tabela 1 - Feira de Santana: População total rural, urbana e da cidade; Taxa de Urbanização; e Percentual da população da cidade sobre a total, $1940-2010$

\begin{tabular}{ccccc}
\hline Períodos & $\begin{array}{c}\text { População } \\
\text { Total }\end{array}$ & $\begin{array}{c}\text { População } \\
\text { Rural }\end{array}$ & $\begin{array}{c}\text { População } \\
\text { Urbana }^{1}\end{array}$ & $\begin{array}{c}\text { Taxa de } \\
\text { Urbanização }^{2}\end{array}$ \\
\hline 1940 & 83.268 & 63.518 & 19.750 & 23,72 \\
1950 & 107.205 & 73.928 & 33.277 & 31,04 \\
1960 & 139.747 & 91.358 & 48.389 & 34,63 \\
1970 & 187.290 & 55.570 & 131.720 & 70,33 \\
1980 & 291.506 & 57.875 & 233.631 & 80,15 \\
1991 & 406.447 & 56.890 & 349.557 & 86,00 \\
2000 & 480.949 & 49.219 & 431.730 & 89,77 \\
2010 & 556.642 & 46.007 & 510.635 & 91,73 \\
\hline
\end{tabular}

Fonte: IBGE (1940, 1950, 1960, 1970, 1980, 1991, 2000, 2010).

Notas: 1 - São inclusas as pessoas que vivem nas sedes de outros distritos e povoados; 2 - Percentual da população urbana sobre a total; 3 - Apenas os dados da população que vive na sede do município - a cidade.

A Tabela 1, que ilustra a Taxa de Urbanização, demonstra o movimento migratório da zona rural para a cidade e o constante aumento do êxodo. Em 1940, em média, havia três moradores no campo para cada morador da zona urbana. Em 2010 o fenômeno que se percebe, com base nos dados, é de que há 10 moradores na zona urbana para apenas 1 morador da zona rural.

Esses movimentos migratórios são os responsáveis pelo acelerado adensamento das áreas em torno do anel viário de Feira de Santana e das margens das rodovias, através de ocupações, loteamentos populares e aglomerados habitacionais, que formavam, em 2009, os 44 bairros da cidade. Em sua maioria, 8 bairros eram constituídos por população de baixa e média renda, o que gera com isso uma elevada densidade demográfica na sua sede. (CARMO, 2009)

Desde a sua origem até o final da década de 1960, quando no município de Feira de Santana a população rural se igualava à urbana, que em sua maioria residia de forma concentrada no Centro da cidade, o espaço territorial urbano limitava-se ao atual Anel de Contorno, Avenida de Contorno ou Avenida Eduardo Fróes da Mota (CARMO, 2009).

Com base nos dados, é possível concluir que mais de $90 \%$ da população do município de Feira de Santana, em 2010, vivia na área urbana. Esse aumento da taxa de urbanização é consequência da posição estratégica da cidade, que é um centro econômico importante que exerce a função de entreposto do Sertão Baiano, tendo grande área de influência nas cidades circunvizinhas, bem como de atração de parte do êxodo rural. Em virtude desse crescimento da população urbana, Feira de Santana passou a encontrar problemas de infraestrutura, que também ocorrem em boa parte das grandes e médias, um dos principais problemas reside na questão da mobilidade urbana.

O aumento populacional não acompanhado por um planejamento urbano em infraestrutura adequado colocou Feira de Santana no rol das médias cidades brasileiras que passaram a sofrer com problemas de mobilidade. Ruas e avenidas congestionadas, carros parados, intenso fluxo de motocicletas, buzinaço, semáforos abrem e fecham e condutores não saem do lugar, motoristas irritados, outros param em filas duplas, em locais proibidos, horário de carga e descarga inadequados etc. Esse cenário caracteriza atualmente o Centro de Feira de Santana, sobremodo em horário de intenso fluxo de veículos. (ADRIANI, 2012)

Peixoto (2015) afirma que um projeto de mobilidade urbana para Feira de Santana poderia proporcionar à população as condições necessárias para o seu deslocamento pelas diversas artérias da cidade. Na opinião do autor, esse projeto resolveria, ou ajudaria a resolver, os problemas ocasionados pelo excesso de veículos que circulam na zona urbana, principalmente no centro comercial.

Quem reside em Feira de Santana não consegue se locomover com fluência da sua residência para o trabalho, ou para algum lugar no qual as pessoas tenham necessidade ou simplesmente por desejo de estar, independentemente do tipo de veículo que esteja usando. Ao usuário do transporte coletivo que paga uma tarifa altíssima não é oferecido o mínimo de conforto. A qualidade do serviço prestado é ínfima, não há pontualidade, segurança durante o trajeto e tudo isso causa aos passageiros, insatisfação e estresse. Ao chegarem a seu destino, as pessoas descem do veículo com o aspecto de que vieram de uma batalha (PEIXOTO, 2015)

Para o autor, a mobilidade urbana proporciona a garantia de seguir para o destino pretendido, no horário devido e com tranquilidade. Proporciona ainda a opção de poder deixar seu veículo particular na garagem e se locomover utilizando um sistema de transporte coletivo ideal, até mesmo de bicicleta ou a pé.

Em 2009, Feira de Santana aparecia entre as dez cidades com o maior crescimento na frota de veículos, pois obteve significativa evolução de frota de veículos, principalmente nos períodos entre 2001 a 2009. A evolução no município foi de $123 \%$, conforme informações do Instituto Brasileiro de Geografia e Estatística (IBGE) e do Departamento Nacional de Trânsito (Denatran), vinculado ao Ministério das Cidades. Esse número põe Feira de Santana na nona posição no ranking que compreende 61 cidades brasileiras. (ACORDA..., 2009)

A Tabela 2 ilustra a população total do município de Feira de Santana, a frota total de veículos cadastrados na 3a Circunscrição Regional de Trânsito (CIRETRAN) de Feira de Santana, a taxa de veículos por habitante e o crescimento do número de veículos entre os anos de 2000 e 2016.

Ao considerar o interregno de 15 anos, de 2001 a 2016, a frota total de veículos mais que quadruplicou, visto que era de 60.050 veículos em 2001 e alcançou o número de 252.696 em 2016.

A Tabela 2 ilustra ainda a Taxa de Habitantes por Veículo, que em 2001 era de 8,16 habitantes por veículo, já em 2016 passou a ser 2,46 habitantes por veículo. Se essa tendência se mantiver, em breve, talvez esse número se iguale a um veículo por habitante e ratifica que, na última 
Tabela 2 - Feira de Santana: População total; Frota total de veículos; Taxa de veículo por habitante; e Incremento de Veículos, 2000-2016

\begin{tabular}{ccccc}
\hline Períodos & $\begin{array}{c}\text { População } \\
\text { Total }\end{array}$ & $\begin{array}{c}\text { Frota } \\
\text { Total de } \\
\text { Veículos }\end{array}$ & $\begin{array}{c}\text { Taxa de } \\
\text { habitante } \\
\text { por veículo }\end{array}$ & $\begin{array}{c}\text { Incremento } \\
\text { de veículos }\end{array}$ \\
\hline 2000 & 489.291 & - & - & - \\
2001 & 490.307 & 60.050 & 8,16 & - \\
2002 & 496.625 & 66.444 & 7,47 & 6.394 \\
2003 & 503.900 & 73.381 & 6,87 & 6.937 \\
2004 & 519.173 & 80.318 & 6,46 & 6.937 \\
2005 & 527.625 & 88.718 & 5,95 & 8.400 \\
2006 & 535.820 & 98.724 & 5,43 & 9.949 \\
2007 & 571.997 & 112.728 & 5,07 & 14.004 \\
2008 & 584.497 & 128.095 & 4,56 & 15.367 \\
2009 & 591.707 & 135.800 & 4,36 & 7.705 \\
2010 & 556.642 & 161.889 & 3,44 & 26.089 \\
2011 & 562.466 & 178.221 & 3,16 & 16.332 \\
2012 & 568.099 & 196.706 & 2,89 & 18.485 \\
2013 & 606.139 & 213.947 & 2,83 & 17.241 \\
2014 & 612.000 & 229.924 & 2,66 & 15.977 \\
2015 & 617.528 & 243.427 & 2,54 & 13.503 \\
\hline 2016 & 622.639 & 252.696 & 2,46 & 9.269 \\
\hline
\end{tabular}

Fonte: IBGE (2000, 2001, 2002, 2003, 2004, 2005, 2006, 2007, 2008, 2009, 2010, 2011, 2012, 2013, 2014, 2015, 2016).

Notas: 1 - Até o ano 2000 a contagem dos veículos era feita por Estado da Federação; 2 - Para obtenção da taxa de veículo por habitante considerouse a população total, urbana e rural de Feira de Santana - Bahia; 3 - Os valores de população são considerados as contagens do Censo 2000 e 2010, nos demais anos a população foi estimada pelo IBGE. década, o número de veículos por habitante cresceu bastante e compromete a lógica histórica da valorização do transporte individual no Brasil.

Ainda na mesma tabela é possível perceber que o incremento de veículos diminuiu após 2015, possivelmente em decorrência do fim da política de redução do Imposto sobre Produtos Industrializados (IPI), que onerou o valor dos veículos e causou certa desaceleração no mercado de veículos zero quilômetro. Desde 2012, o governo renovou diversas vezes a redução do tributo, sob a condição de o setor automotivo não demitir e não cortar investimentos. Todavia, em janeiro de 2015, o governo decidiu não mais manter o incentivo. A redução do imposto, iniciada em 2012, não foi prorrogada pelo governo e terminou em dezembro de 2014. (UOL..., 2014)

Ao observar os dados da Tabela 3 é possível concluir que nos últimos 10 anos ocorreu um incremento muito grande da frota de veículos de transporte individual, o que certamente contribuiu para um aumento dos congestionamentos e dos tempos de deslocamento.

A quantidade de automóveis que em 2005 era 47.388 unidades, mais que duplicou em 2016, com 112.948 unidades. Crescimento ainda maior se verifica na frota de motocicletas que em 2005 era 17.590 unidades e em 2016 alcançou a marca de 72.834 unidades, a quantidade mais que quadruplicou em 11 anos.

Aliado a esse crescimento da frota de veículos, muitas famílias sentem as consequências do crescimento imobiliário desordenado e da expansão urbana em Feira de Santana. Com o incentivo ao mercado imobiliário, efetuado pelo governo federal, vários condomínios foram construídos pela cidade e ocupam áreas em bairros afastados do Centro, e, em geral, passa a ser perceptível a "falta de um planejamento" mínimo para garantir aos novos moradores serviços essenciais.

Tabela 3 - Feira de Santana: Frota de Veículos: Automóvel, Caminhão, Caminhão Trator, Camioneta, Micro-ônibus, Motocicleta, Motoneta, Ônibus, Trator de Rodas, Utilitário e Outros, 2005-2016

\begin{tabular}{|c|c|c|c|c|c|c|c|c|c|c|c|c|}
\hline $\begin{array}{c}\text { ANO } \\
\text { VEículOS }\end{array}$ & 2005 & 2006 & 2007 & 2008 & 2009 & 2010 & 2011 & 2012 & 2013 & 2014 & 2015 & 2016 \\
\hline Automóvel & 47.388 & 51.706 & 57.182 & 61.496 & 67.223 & 73.751 & 79.882 & 88.163 & 95.657 & 102.644 & 108.826 & 112.948 \\
\hline Caminhão & 5.273 & 5.716 & 6.079 & 6.291 & 6.694 & 7.506 & 7.883 & 8.321 & 8.476 & 8.801 & 8.967 & 8.987 \\
\hline Caminhão Trator & 740 & 830 & 958 & 1.125 & 1.267 & 1.471 & 1.664 & 1.690 & 1.942 & 2.052 & 2.104 & 2.101 \\
\hline Micro-ônibus & 543 & 575 & 655 & 735 & 801 & 885 & 1.027 & 1.119 & 1.211 & 1.280 & 1.354 & 1.449 \\
\hline Motocicleta & 17.590 & 20.682 & 25.973 & 32.826 & 39.676 & 46.727 & 52.579 & 58.223 & 62.926 & 67.005 & 70.555 & 72.834 \\
\hline Motoneta & 4.245 & 5.010 & 6.158 & 7.376 & 8.690 & 10.223 & 11.644 & 13.236 & 15.093 & 16.686 & 17.969 & 18.834 \\
\hline Ônibus & 775 & 803 & 864 & 954 & 1.043 & 1.122 & 1.180 & 1.201 & 1.304 & 1.334 & 1.440 & 1.510 \\
\hline
\end{tabular}

Fonte: IBGE/DENATRAN (2005, 2006, 2007, 2008, 2009, 2010, 2011, 2012, 2013, 2014, 2015, 2016). 


\section{CONSIDERAÇÕES FINAIS}

Um planejamento urbano de longo prazo é um fator que pode contribuir para melhorar a mobilidade urbana em Feira de Santana, se adequadamente efetivado. Especialistas consideram que um dos maiores problemas da mobilidade urbana foi o crescimento desordenado de boa parte das metrópoles brasileiras. Isso porque, via de regra, a periferia foi ocupada tardiamente pela parcela mais pobre da população, ainda que nas últimas décadas as classes médias e alta as tenham também ocupado. Como resultado, grande parte das pessoas mora longe do trabalho e precisa realizar muitos deslocamentos no dia a dia. Nesse sentido, é preciso mudar a maneira de conceber os bairros em Feira de Santana. É preciso deixá-los mais densos, e com usos mistos. É preciso ter bairros com desenhos inteligentes: mais completos, bairros com acesso a comércio, serviços e equipamentos que não demandem grandes deslocamentos. É preciso, por exemplo que se conceba a descentralização de certos serviços, como bancários, lotéricas, públicos, por exemplo, e desse modo evitarse esses deslocamentos desnecessários para o Centro da cidade.

A falta de políticas efetivas de melhoria da mobilidade urbana e de fomento ao uso do transporte coletivo de qualidade também é outro fator que contribui de maneira significativa para que os usuários utilizem mais veículos de passeio e não utilizem o transporte coletivo.

É preciso também elaborar projetos de longo prazo para a reestruturação do sistema viário. O trânsito de Feira de Santana tem problemas visíveis há algum tempo, e algumas medidas, claramente sem planejamento, não resolvem a questão de forma efetiva, apenas transferem engarrafamentos para outras partes da cidade. Portanto, são necessários estudos aprofundados e um planejamento adequado do sistema viário que contemple ruas e avenidas mais largas para os diversos bairros, sejam atuais ou futuros.

Um fato que parece expressivo em Feira de Santana é a cultura de pensar por modal, pensar o deslocamento com um tipo de transporte apenas: ou seja, ou o usuário deslocase por carro, ou vai a pé, ou vai de ônibus. Porém, para um melhor aproveitamento e eficiência o sistema poderia estar associado a outros modais, bem como criar um sistema tarifário de bilhete único. E essa intermodalidade não necessariamente precisa ocorrer somente entre sistemas coletivos, poderia ocorrer entre o público e o privado.

É necessário pensar em Feira de Santana em outros modais, como o VLT, a exemplo do que foi implantado em Sobral, no Ceará, uma cidade com 180 mil habitantes, para que a partir do sistema já existente possa ser possível gerar novas possibilidades que atendam a demanda dos usuários. Todavia, isso só é possível com planejamento em longo prazo.

\section{REFERÊNCIAS}

ACORDA CIDADE. Frota de veículos cresce no Brasil: Feira está entre as 10 cidades. Disponível em: <http://www.acordacidade. com.br/noticias/1148/frota-de-veiculos-cresce-no-brasil-feiraesta-entre-as-10-cidades.html>. Acesso: 15 dez. 2016.

O preço do crescimento desordenado em Feira de Santana.Disponível em: <http://www.acordacidade.com.br/ noticias/173896/o-preco-do-crescimento-desordenado-emfeira-de-santana.html>. Acesso: 15 dez. 2016.

ADRIANI, Guilherme. Caos no trânsito do Centro de Feira de Santana. Disponível em: <http://www.jornalfolhadoestado. com/noticias/1274/caos-no-transito-do-centro-de-feira-desantana>. Acesso: 05 dez. 2016.

BERTINI, Roberto L. You are the traffic jam: an examination of congestion measures. In: 85th Annual meeting of the transportation research Board. Washington, DC, Nov. 2005.

CARMO, Rene Becker Almeida. A urbanização e os assentamentos subnormais de Feira de Santana. 2009. 360f. Tese (Doutorado) - Programa de Estudos Pós-Graduados em Ciências Sociais. Departamento de Ciências Sociais, Pontífica Universidade Católica, São Paulo, 2009.

CIFS. Centro Industrial de Feira de Santana. Disponível em: <http://www.cifs.com.br/historico.php>. Acesso: 05 jan. 2017.

DENATRAN - DEPARTAMENTO NACIONAL DE TRÂNSITO. Frota de veículos. Disponível em: <http://www.denatran.gov.br/ frota.htm>. Acesso: 05 jan. 2017.

FEIRA DE SANTANA. A noite feirense no início dos anos 70. Disponível em: <http://www.feiradesantana.ba.gov.br/ feiraemhistoria.asp>. Acesso: 05 jan. 2017.

FALCÃO, Cristiane; CAMPOS, Luciana. Origem de Feira de Santana. Disponível em: <http://origem-de-feira.blogspot.com. br/2008/06/origem-de-feira-santana.html>. Acesso: 15 jan. 2018

FEIRENSES. Quando o transporte público em Feira de Santana era feito com Kombis. Disponível em: <http://feirenses.com/ transporte-feira-de-santana-kombis/>. Acesso: 20 dez. 2016.

FERREIRA, Joildo. Mobilidade urbana de Feira de Santana. Disponível em: <http://joildoferreira.blogspot.com.br/2011/ 09/postage-em-aguardo.html>. Acesso: 08 dez. 2016.

GOMES, Tatiane Sátiro. Mapa de Localização de Feira de Santana-Bahia/Brasil. Feira de Santana: GEOTEC/UEFS, 2011.

IBGE. Cidades: Feira de Santana. Disponível em: <http://cod. ibge.gov.br/3HC>. Acesso: 03 jun. 2016.

Enciclopédia dos Municípios Brasileiros. Rio de Janeiro: IBGE, 1958b. Volume XXI.

Censo Demográfico 2000. Disponível em: <http:// www.ibge.gov.br/censo2000>. Acesso: 03 jun. 2016.

Censo Demográfico 2010. Disponível em: <http:// www.ibge.gov.br/censo2010>. Acesso: 03 jun. 2016.

LIMA, Renam Paiva de Souza. Mobilidade Urbana. Disponível em:<http://educacao.globo.com/geografia/assunto/ 
atualidades/mobilidade-urbana.html>. Acesso: 08 out. 2015.

PEIXOTO, Alberto. Mobilidade urbana em Feira de Santana. Disponível em: <http://www.jornalgrandebahia.com.br/2015/ 03/mobilidade-urbana-em-feira-de-santana/>. Acesso: 08 out. 2015.

PENA, Rodolfo F. Alves. Mobilidade urbana no Brasil: Brasil Escola. Disponível em: <http://www.brasilescola.com/geografia/ mobilidade-urbana-no-brasil.htm>. Acesso: 05 out. 2015.

Êxodo rural no Brasil. Disponível em: <http:// mundoeducacao.bol.uol.com.br/geografia/Exodo-rural-nobrasil.htm>. Acesso: 02 dez. 2016.

PEREIRA, R.M.; SCHWANEN, T. Tempo de deslocamento casa-trabalho no Brasil (1992-2003): Diferenças entre Regiões Metropolitanas, níveis de renda e sexo. Brasília: IPEA, 2013.

POPPINO, R. E. Feira de Santana. Salvador: Itapuã, 1968.

QUEIROZ, Guilherme. Crescimento da economia está ligado à mobilidade nas cidades.Disponível em: <http://www. portaldaindustria.com.br/cni/imprensa/2013/11/1,28774/ crescimento-da-economia-esta-ligado-a-mobilidade-nascidades.html>. Acesso: 17 jul. 2015.

RESENDE, Paulo Tarso Vilela de; SOUSA, Paulo Renato de. Mobilidade Urbana nas Grandes Cidades Brasileiras: um estudo sobre os impactos do congestionamento. In: XII SIMPÓSIO DE ADMINISTRAÇÃO DA PRODUÇÃO, LOGÍSTICA E OPERAÇÕES INTERNACIONAIS, 21. 2009, São Paulo.
Anais eletrônicos... São Paulo: FGV, 2009. Disponível em: <http://www.simpoi.fgvsp.br/arquivo/2009/artigos/E2009_ T00138_PCN41516.pdf>. Acesso: 17 jul. 2015.

SANTO, Sandra Medeiros. A expansão urbana, o Estado e as águas em Feira de Santana/Bahia (1940 - 2010). 2012. 275 f. Tese (Doutorado) - Programa de Pós-Graduação em Arquitetura e Urbanismo, Faculdade de Arquitetura, Universidade Federal da Bahia, Salvador, 2012.

SIQUEIRA, Graziana Donata Punzi de; LIMA, Josiane Palma. A contribuição das políticas públicas de mobilidade urbana para o desenvolvimento sustentável das cidades. In: VI SIMPÓSIO NACIONAL DE CIÊNCIA, TECNOLOGIA E SOCIEDADE. 6., 2015, Rio de Janeiro. Anais eletrônicos... Rio de Janeiro: UFRJ, 2015. Disponível em: <http://www.rio2015. esocite.org/resources/anais/5/1440766741_ARQUIVO_ ArtigoparaoTECSOC.pdf>. Acesso: 17 jul. 2016.

UOL. Redução de IPI para carros termina e imposto fica maior a partir do dia 1․ Disponível em: <https://economia. uol.com.br/noticias/redacao/2014/12/31/reducao-deipi-para-carros-termina-e-imposto-fica-maior-a-partir-deamanha.htm>. Acesso: 20 dez. 2016.

UPB. Feira de Santana, Alagoinhas e Santo Antônio de Jesus: Elas estão preparadas para crescer?.Disponível em:<http://www.upb.org.br/noticias/feira-de-santanaalagoinhas-e-santo-antonio-de-jesus-elas-estao-preparadaspara-crescer/>. Acesso: 15 dez. 2016. 